\title{
First report of in-tissue esophagogastric transit migration of an over-the-scope clip
}

\author{
Vincent Zimmer ${ }^{\mathrm{a}, \mathrm{b}}$ \\ Marienhausklinik St. Josef Kohlhof, Neunkirchen; Saarland University Medical Center, Saarland University, Homburg, \\ Germany
}

A 33-year-old male underwent emergent upper endoscopy because of acute food impaction. Esophagogastroduodenoscopy (EGD) proved highly suggestive of underlying eosinophilic esophagitis (EoE), yielding a presumptive EoE endoscopic reference score (EREFS) of 7 with extensive distal food impaction [1]. After endoscopic disimpaction using various maneuvers, finally including the push technique, a circumscript deeper esophageal wall injury occurred just above the $\mathrm{Z}$ line (Fig. 1A). This was treated by the intraprocedural deployment of an 11/6t over-the-scope clip (OTSC; Ovesco Endoscopy, Tübingen, Germany) and the patient's subsequent clinical course was uncomplicated (Fig. 1B). After histopathological confirmation of EoE, topical treatment was initiated with an orodispersible budesonide tablet ( $1 \mathrm{mg}$ b.i.d.), recently marketed in Europe, and the patient was scheduled for repeat EGD 6 weeks later [2]. With improving EoE, as reflected by a reduction in the EREFS to 2, the OTSC was no longer detectable in the distal esophagus. Notably, the $\mathrm{Z}$ line above which the clip had initially been deployed proved well demarcated circumferentially, thus implying true in-tissue migration instead of the clip having merely been pulled into the stomach (Fig. 1C). A retroflexed view in the stomach showed the OTSC still in situ and attached to the mucosa with ample of granulation tissue, giving rise to a typical OTSC-related pseudopolyp (Fig. 1D).

OTSC applications have gained much momentum in recent years and provide a powerful backup strategy in modern endoscopy, mostly for the management of transmural luminal defects and/or gastrointestinal bleeding, with limited potential for clinically relevant complications [3]. Although no distinct clinical and/or endoscopic complication whatsoever arose in

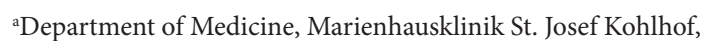
Neunkirchen (Vincent Zimmer); ${ }^{\mathrm{b}}$ Department of Medicine II, Saarland University Medical Center, Saarland University, Homburg (Vincent Zimmer), Germany

Conflict of Interest: None

Correspondence to: Dr. Vincent Zimmer, Department of Medicine, Marienhausklinik St. Josef Kohlhof, Klinikweg 1-5, 66539 Neunkirchen, Germany, e-mail: vincent.zimmer@gmx.de

Received 6 July 2020; accepted 28 July 2020; published online 2 October 2020

DOI: https://doi.org/10.20524/aog.2020.0539

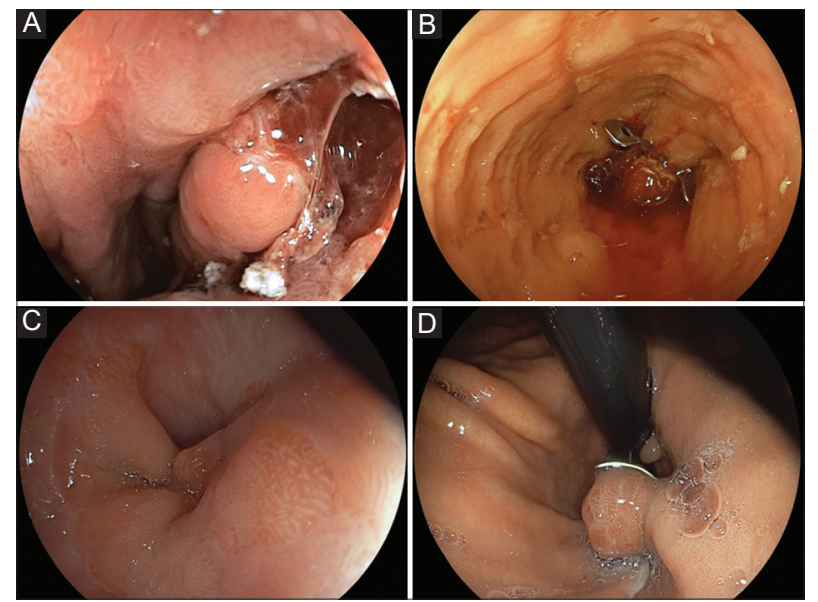

Figure 1 (A) Deeper, although not clear-cut transmural defect just above the $\mathrm{Z}$ line during endoscopic disimpaction of an eosinophilic esophagitis (EoE)-related food bolus. (B) Successful deployment of an over-the-scope clip (OTSC; Ovesco Endoscopy, Tübingen, Germany); note also endoscopic signs of EoE corresponding to an endoscopic reference score of 7. (C) Illustration of a fully preserved $\mathrm{Z}$ line above which the OTSC was initially deployed. (D) Scope inversion within the stomach excluded OTSC detachment but rather suggested in-tissue esophagogastric migration, with the OTSC still attached to the mucosa

this individual patient, this well-documented illustration of in-tissue esophagogastric transit migration is altogether novel, most likely related to constant stomach-directed peristaltic forces, and may add to our knowledge of in vivo biomechanical interactions and the behavior of OTSC clips.

\section{References}

1. Hirano I, Moy N, Heckman MG, Thomas CS, Gonsalves N, Achem SR. Endoscopic assessment of the oesophageal features of eosinophilic oesophagitis: validation of a novel classification and grading system. Gut 2013;62:489-495.

2. Lucendo AJ, Miehlke S, Schlag C, et al. Efficacy of budesonide orodispersible tablets as induction therapy for eosinophilic esophagitis in a randomized placebo-controlled trial. Gastroenterology 2019;157:74-86.

3. Asokkumar R, Chin YK, Soetikno R. Complications with over the scope clip: how can we prevent it? Gastrointest Endosc Clin N Am 2020;30:75-89. 